Research Paper

\title{
Increased Expression of Several Collagen Genes is Associated with Drug Resistance in Ovarian Cancer Cell Lines
}

\author{
Radosław Januchowski ${ }^{\bowtie}$, Monika Świerczewska ${ }^{1}$, Karolina Sterzyńska1, Karolina Wojtowicz' ${ }^{1}$, Michał \\ Nowicki ${ }^{1}$, Maciej Zabel ${ }^{1,2}$ \\ 1. Department of Histology and Embryology, Poznań University of Medical Sciences, Poland; \\ 2. Department of Histology and Embryology, Wroclaw Medical University, Poland. \\ $\square$ Corresponding author: Radosław Januchowski, mailing address: Department of Histology and Embryology, Poznan University of Medical Sciences, \\ Święcickiego 6 St., Poznań, post code 61-781, phone number +48618546419, fax number +48 618546440, email address: rjanuchowski@ump.edu.pl.
}

() Ivyspring International Publisher. Reproduction is permitted for personal, noncommercial use, provided that the article is in whole, unmodified, and properly cited. See http://ivyspring.com/terms for terms and conditions.

Received: 2016.02.25; Accepted: 2016.05.23; Published: 2016.06.25

\begin{abstract}
Ovarian cancer is the most lethal gynaecological cancer. The main reason for the high mortality among ovarian cancer patients is the development of drug resistance. The expression of collagen genes by cancer cells can increase drug resistance by inhibiting the penetration of the drug into the cancer tissue as well as increase apoptosis resistance. In this study, we present data that shows differential expression levels of collagen genes and proteins in cisplatin- (CIS), paclitaxel- (PAC), doxorubicin- (DOX), topotecan- (TOP), vincristine- (VIN) and methotrexate- (MTX) resistant ovarian cancer cell lines. Quantitative real-time polymerase chain reactions were performed to determine the mRNA levels. Protein expression was detected using Western blot and immunocytochemistry assays. In the drug resistant cell lines, we observed the upregulation of eight collagen genes at the mRNA level and based on these expression levels, we divided the collagen genes into the following three groups:

1. Genes with less than a 50-fold increase in expression: COLIAI, COL5A2, COLI2AI and COLI 7AI. 2. Genes with greater than a 50-fold increase in expression: COLIA2, COLI5AI and COL2IAI. 3. Gene with a very high level of expression: COL3AI. Expression of collagen (COL) proteins from groups 2 and 3 were also confirmed using immunocytochemistry. Western blot analysis showed very high expression levels of COL3Al protein, and immunocytochemistry analysis showed the presence of extracellular COL3AI in the WITR cell line. The cells mainly responsible for the extracellular COL3Al production are aldehyde dehydrogenase-1Al (ALDHIAl) positive cells. All correlations between the types of cytostatic drugs and the expression levels of different $\mathrm{COL}$ genes were studied, and our results suggest that the expression of fibrillar collagens may be involved in the TOP and PAC resistance of the ovarian cancer cells. The expression pattern of $\mathrm{COL}$ genes provide a preliminary view into the role of these proteins in cytostatic drug resistance of cancer cells. The exact role of these $\mathrm{COL}$ genes in drug resistance requires further investigation.
\end{abstract}

Key words: collagen gene expression, drug resistance, ovarian cancer, stem cells, anticancer therapy.

\section{Introduction}

Epidemiological data has shown that epithelial ovarian cancer (EOC) is the most lethal gynaecological malignancy in the world [1]. Most patients are diagnosed at stage III or IV, according to the FIGO classification, and have poor prognosises
[2]. Regardless of the clinical stage, surgery and chemotherapy are the main treatment options for ovarian cancer [3]. At the beginning of chemotherapy, ovarian cancer is usually responsive. Unfortunately, approximately $80 \%$ of patients with a good response 
to first-line chemotherapy at the beginning of treatment will have a recurrence and will require continuation of treatment. The first line of chemotherapeutic treatment includes a combined regimen of platinum and taxane [4]. The second line of treatment usually involves taxane, cisplatin (CIS), topotecan (TOP), and doxorubicin (DOX) $[5,6]$.

The basic reason for the reduced effectiveness of chemotherapy is due to the drug resistance of cancer cells. In general, we can divide the mechanisms of cancer drug resistance into two main categories, as follows: 1. mechanisms of drug resistance specific to cancer cells and 2. tissue specific mechanisms of drug resistance in cancer. Cellular mechanisms of drug resistance are extensively described in literature. In PubMed, we can find thousands of papers about these mechanisms. Cellular mechanisms of drug resistance include a lower accumulation of the drug in the cells, change of localization of the drug in the cell, faster inactivation of the drug, faster repair of DNA and cellular membranes damaged by the drug as well as increased ability to tolerate these damages, changes in molecular targets that make the cells insensitive or less sensitive to the drugs' actions, changes in gene expression, and changes in regulation of apoptosis. The most significant cellular mechanism of drug resistance is the active removal of the therapeutic agents from the cancer cells through transport proteins that belong to the $\mathrm{ABC}$ family, and the best known example is glycoprotein P (P-gp) [7].

According to the cancer stem cell (CSC) model of drug resistance development in cancer, CSCs are responsible for resistance to chemotherapy. These cells are differentiated from other cancer cells by the expression of aldehyde dehydrogenase-1A1 (ALDH1A1) as well as high levels of expression of drug transporters and other genes related to drug resistance [8]. The expression of ALDH1A1 positive cells was reported in ovarian cancer and in ovarian cancer cell lines $[9,10]$ and correlated with resistance to CIS and PAC treatments [10].

The cellular mechanisms of drug resistance are mainly investigated in standard, 2D (two dimensional) cell culture conditions, where cells grow as a monolayer. However, in the human body, cancer is not made of a single layer of cells but is a multicellular structure that develops into a cancer specific tissue composed of cancer cells, basement membrane and cancer blood vessels. Thus, the tumour is an organ-like structure with a set of transport barriers to drug delivery. Growth-induced solid stress and an underdeveloped vascular system are some of the limitations to drug delivery in these cells [11, 12]. A dense cellular structure limits drug diffusion into cells that are localized away from the blood vessels [12-14]. Cancer cells also express large amounts of extracellular matrix (ECM) components such as collagens and proteoglycans that further limit the diffusion of therapeutic agents into the cancer tissue $[12,15]$. Dense and tortuous tumour ECM can significantly limit drug delivery [12]. The speeds of diffusion of the molecules are inversely correlated to the levels of fibrillar collagen, its organization, and spatial orientation [16-19]. ECM molecules, including collagen, may limit drug diffusion [20]. Some cytostatics, such as DOX, Methotrexate (MTX), Vinblastine and Paclitaxel (PAC) bind to cellular macromolecules that limit their availability to the tumour tissue [15].

The expression of ECM components including collagens is not limited to tumour tissue but was also observed in many breast [21] and ovarian cancer drug-resistant cell lines [22-24], which indicates that the expression of collagens can play an important role in both tissue mediated drug resistance and drug resistance at the cellular level. The interaction of collagens and other ECM components with cancer cells can result in cancer drug resistance. These interactions can change the apoptosis sensitivity and increase the drug resistance of cancer cells [25]. This type of drug resistance is designated as cell adhesion-mediated drug resistance (CAM-DR) [26, 27] and is observed both in vitro [22] and in vivo [28]. An example of this resistance is the resistance of the A2780 ovarian cancer cell line to cisplatin (CIS). The A2780 ovarian cancer cell line, which is sensitive to CIS, when cultured in the presence of collagen VI, develops resistance to this drug in vitro. This resistance probably results from the interactions of collagen with the cellular receptors that leads to the inhibition of apoptosis [22]. Sethi et al. showed that small cell lung cancer (SCLC) is surrounded by ECM at both the primary and the metastatic sites. The interaction of cancer cells with ECM through the $\beta 1$-integrin resulted in the inhibition of apoptosis that was induced by chemotherapy [28].

This study shows the changes in the collagen gene expression levels in the CIS (W1CR, A2780CR1, A2780CR2, SKOV-3CR1, SKOV-3CR2), PAC (W1PR1, W1PR2, A2780PR1, A2780PR2), DOX (W1DR, A2780DR1, A2780DR2), TOP (W1TR, A2780TR1, A2780TR2, SKOV-3TR1, SKOV-3TR2), Vincristine (VIN) (W1VR) and MTX (W1MR) resistant ovarian cancer cell lines and also provides evidence for the relationship between ALDH1A1 (marker of CSCs) and COL3A1 expression. 


\section{Materials and Methods}

\section{Reagents and Antibodies}

Methotrexate, cisplatin, doxorubicin, vincristine, topotecan, and paclitaxel were obtained from Sigma (St. Louis, MO, US). RPMI-1640, MEM, DMEM, foetal bovine serum, antibiotic-antimycotic solution, L-glutamine and RIPA buffer were also purchased from Sigma (St. Louis, MO, US). The protease inhibitor cocktail was purchased from Roche Diagnostics $\mathrm{GmbH}$ (Mannheim, Germany). Goat anti-COL1A2 polyclonal antibody (Ab) (M-19), goat anti-COL3A1 polyclonal $\mathrm{Ab}$ (C-15), goat anti-COL15A1 polyclonal $\mathrm{Ab} \quad(\mathrm{N}-20)$ goat anti-COL21A1 polyclonal Ab (D-13), rabbit anti-GADPH polyclonal Ab (FL-335), donkey anti-goat horseradish peroxidase (HRP)-conjugated $\mathrm{Ab}$ and goat anti-rabbit HRP-conjugated $\mathrm{Ab}$ were purchased from Santa Cruz Biotechnology (Santa Cruz, CA, US). Rabbit monoclonal anti-ALDH1A1 antibody (EP1933Y) was purchased from Abcam (Cambridge, UK). The MFP488 and MFP590 fluorescent secondary antibodies were obtained from MoBiTec (Goettingen, Germany). The mounting medium with DAPI was obtained from Santa Cruz Biotechnology (Santa Cruz, CA, US).

\section{Cell lines and cell culture}

In this study, we used three ovarian cancer cell lines, the established ovarian cancer cell lines A2780 and SKOV-3 as well as the primary ovarian cancer cell line $\mathrm{W} 1$.

The human ovarian carcinoma A2780 and SKOV-3 cell lines were purchased from ATCC. A2780 sublines that were resistant to CIS [A2780CR1 and A2780CR2 (A2780 cisplatin resistant)], PAC [A2780PR1 and A2780PR2 (A2780 paclitaxel resistant)], DOX [A2780DR1 and A2780DR2 (A2780 doxorubicin resistant)] and TOP [A2780TR1 and A2780TR2 (A2780 topotecan resistant)] were generated by exposing A2780 cells to the relevant drugs at incrementally increasing concentrations. SKOV-3 sublines that were resistant to CIS [SKOV-3CR1 and SKOV-3CR2 (SKOV-3 cisplatin resistant)] and TOP [SKOV-3TR1 and SKOV-3TR2 (SKOV-3 topotecan resistant)] were generated by exposing SKOV-3 cells to the relevant drugs at incrementally increasing concentrations.

The human primary ovarian cancer cell line W1 was established using ovarian cancer tissue obtained from an untreated patient. W1 sublines resistant to CIS [W1CR (W1 cisplatin resistant)], DOX [W1DR (W1 doxorubicin resistant)], TOP [W1TR (W1 topotecan resistant)], PAC [W1PR1 and W1PR2 (W1 paclitaxel resistant)], MTX [W1MR (W1 methotrexate resistant)] and VIN [W1VR (W1 vincristine resistant)] were obtained by exposing W1 cells to the drugs at incrementally increasing concentrations.

All resistant cell lines were generated in our laboratory. The cells were seed in the concentration of 10 thousand cells $/ \mathrm{cm} 2$ in $25 \mathrm{~cm} 2$ flask in dedicated media supplemented with appropriate drug. The established concentrations of the initial drugs exposure were of MTX $2 \mathrm{ng} / \mathrm{mL}$, CIS $20 \mathrm{ng} / \mathrm{mL}$, Dox $10 \mathrm{ng} / \mathrm{mL}$, Vin 0,5 ng/mL, TOP 0,5 ng/mL, and PAC $1 \mathrm{ng} / \mathrm{mL}$. Each cell line was exposed three times for 3-day periods during a 3-6-week period allowing for growth recovery between cycles. The drug dose was doubled after the completion of three cycles and the procedure was repeated until the final drug levels were achieved. The final concentrations used for selecting the resistant cells were $1000 \mathrm{ng} / \mathrm{ml} \mathrm{CIS,} 1100$ ng/ml PAC, $100 \mathrm{ng} / \mathrm{ml}$ DOX, $24 \mathrm{ng} / \mathrm{ml}$ TOP, 10 $\mathrm{ng} / \mathrm{ml} \mathrm{VIN}$ and $24 \mathrm{ng} / \mathrm{ml}$ MTX. These concentrations were chosen based on the results of Dietel et al., 1997 [29], and were two-fold higher than the plasma concentrations of the relevant drugs 2 hours after intravenous administration. The drug sensitivity of the sensitive and the drug resistant cell lines were confirmed by the MTT cell survival assay.

All of the cell lines were maintained as monolayers in complete medium [MEM medium (A2780), DMEM medium (SKOV-3) and RPMI-1640 medium (W1) supplemented with $10 \%$ (v/v) foetal bovine serum, 2 pM L-glutamine, penicillin (100 units $/ \mathrm{ml})$, streptomycin $(100$ units $/ \mathrm{ml})$ and amphotericin B $(25 \mu \mathrm{g} / \mathrm{ml})]$ at $37^{\circ} \mathrm{C}$ in a $5 \% \mathrm{CO}_{2}$ atmosphere.

\section{Examination of Gene Expression by Using QPCR}

The changes in COL1A1, COL1A2, COL3A1, COL5A2, COL12A1, COL15A1, COL17A1 and COL21A1 expression in the W1, A2780, SKOV-3 and drug-resistant cell lines were examined. RNA was isolated using the GeneMATRIX Universal RNA purification kit (EURx Ltd.) as described by the manufacturer's protocol. Reverse transcription was performed using the M-MLV reverse transcriptase (Invitrogen) using a thermal cycler (Veriti 96 well Thermal Cycler), as described in the manufacturer's protocol. Two micrograms of RNA was used for cDNA synthesis. Real-time PCR was performed using the 7900HT Fast Real-Time PCR System (Applied Biosystems), Maxima SYBR Green/ROX qPCR Master Mix (Fermentas) and sequence-specific primers as indicated in Table 1. Glyceraldehyde-3-phosphate dehydrogenase $(G A D P H), \quad \beta$-actin, hypoxanthineguanine phosphoribosyltransferase 1 (HRPT1) and beta-2-microglobulin $(\beta 2 M)$ served as the normalizing 
genes (geometric mean) for the gene expressions being analysed. Gene expressions were analysed using the relative quantification $(R Q)$ method. The RQ method estimates the differences in gene expression against a calibrator (drug sensitive line) (RQ of the calibrator $=1)$. The drug sensitive $(\mathrm{W} 1, \mathrm{~A} 2780$ and SKOV-3) cell lines were used as the calibrators. The analysis was conducted using the following standard formula: $\mathrm{RQ}=2^{-\Delta \Delta \mathrm{Ct}}$ (where $\Delta \Delta \mathrm{Ct}=\Delta \mathrm{Ct}$ of the sample (drug-resistant line) - $\Delta \mathrm{Ct}$ of the calibrator (drug sensitive line)). The graphs were plotted using Sigma Plot.

Table 1. Oligonucleotide sequences used for Q-PCR analysis.

\begin{tabular}{|c|c|c|c|}
\hline Transcript & Sequence $\left(5^{\prime}-3^{\prime}\right.$ direction) & $\begin{array}{l}\text { ENST number } \\
\text { http:// www. } \\
\text { ensembl.org }\end{array}$ & $\begin{array}{l}\text { Product } \\
\text { size (bp) }\end{array}$ \\
\hline COL1A1 & $\begin{array}{l}\text { ACGTCCTGGTGAAGTTGGTC } \\
\text { ACGCTGTCCAGCAATACCTT }\end{array}$ & 00000225964 & $124 \mathrm{bp}$ \\
\hline COL1A2 & $\begin{array}{l}\text { TCAAGGTTTCCAAGGACCTG } \\
\text { TTTCCAGGGTGACCATCTTC }\end{array}$ & 00000297268 & $117 \mathrm{bp}$ \\
\hline COL3A1 & $\begin{array}{l}\text { AAGGTCCAGCTGGGATACCT } \\
\text { CACCCTTTAATCCAGGAGCA }\end{array}$ & 00000304636 & $105 \mathrm{bp}$ \\
\hline COL5A2 & $\begin{array}{l}\text { CCAGGAGTTCCAGGTTTCAA } \\
\text { CAACTGTTCCTGGGTCACCT }\end{array}$ & 00000374866 & $130 \mathrm{bp}$ \\
\hline COL12A1 & $\begin{array}{l}\text { GTCCCAGGATGAGGTCAAGA } \\
\text { TGGCAAGCTCATTGTAGTCG }\end{array}$ & 00000322507 & $101 \mathrm{bp}$ \\
\hline COL15A1 & $\begin{array}{l}\text { CTGGGAGTCCAGAGCTCATC } \\
\text { ATCAAGTGGAGGACCTGGTG }\end{array}$ & 5001 & $p$ \\
\hline COL17A1 & $\begin{array}{l}\text { ACCATCACAGGCGAGACTTT } \\
\text { GCACAGCCAGAATGTCTTCA }\end{array}$ & 00000353479 & $p$ \\
\hline COL21A1 & $\begin{array}{l}\text { ACAGAACAACCGGGAGACAG } \\
\text { TTCCCGGAGGACAAATACAG }\end{array}$ & 00000244728 & $110 \mathrm{bp}$ \\
\hline GADPH & $\begin{array}{l}\text { GAAGGTGAAGGTCGGAGTCA } \\
\text { GACAAGCTTCCCGTTCTCAG }\end{array}$ & 00000229239 & $199 \mathrm{bp}$ \\
\hline$\beta$-actin & $\begin{array}{l}\text { TCTGGCACCACACCTTCTAC } \\
\text { GATAGCACAGCCTGGATAGC }\end{array}$ & 00000331789 & $169 \mathrm{bp}$ \\
\hline HRPT1 & $\begin{array}{l}\text { CTGAGGATTTGGAAAGGGTG } \\
\text { AATCCAGCAGGTCAGCAAAG }\end{array}$ & 00000298556 & $156 \mathrm{bp}$ \\
\hline$\beta 2 \mathrm{M}$ & $\begin{array}{l}\text { CGCTACTCTCTCTTTCTGGC } \\
\text { ATGTCGGATGGATGAAACCC }\end{array}$ & 00000558401 & $133 \mathrm{bp}$ \\
\hline
\end{tabular}

For amplification, $12.5 \mu \mathrm{L}$ of Maxima SYBR Green/ROX qPCR Master Mix (Fermentas), $1 \mu \mathrm{L}$ of each primer (Oligo, Warsaw, Poland) (Table 1), $9.5 \mu \mathrm{L}$ of water, and $1 \mu \mathrm{L}$ of cDNA solution were mixed together. One RNA sample from each preparation was processed without the RT-reaction to provide a negative control in the subsequent PCR reaction. Sample amplification included a hot start $\left(95^{\circ} \mathrm{C}, 15\right.$ minutes) followed by 40 cycles of denaturation at $95^{\circ} \mathrm{C}$ for 15 seconds, annealing at $60^{\circ} \mathrm{C}$ for 30 seconds, and extension at $72^{\circ} \mathrm{C}$ for 30 seconds. After amplification, melt curve analysis was conducted to analyse the product melting temperatures. The amplification products were also resolved using 3\% agarose gel electrophoresis and visualized by ethidium bromide staining.

\section{SDS-PAGE and Western Blot Analysis of COL3AI}

The cells $\left(1 \times 10^{6}\right.$ cells $/ 50 \mu$ L lysis buffer $)$ were lysed in RIPA buffer containing protease inhibitor cocktail (ROCHE) for $60 \mathrm{~min}$ at $4^{\circ} \mathrm{C}$. The lysates were centrifuged at $12000 \times \mathrm{g}$ for $15 \mathrm{~min}$ at $4^{\circ} \mathrm{C}$, and protein concentrations were determined using the Bio-Rad (Hercules, CA) protein assay system. Thirty micrograms of protein from each sample was resuspended in $40 \mu \mathrm{L}$ of a solution containing $200 \mathrm{mM}$ Tris- $\mathrm{HCl}$ ( $\mathrm{pH}$ 6.8), 5\% SDS, 10\% glycerol, $0.25 \%$ 2 -mercaptoethanol, and $0.1 \%$ bromophenol blue. The resuspended protein was loaded into each well and separated on a 7\% Tris-glycine gel using the SDS-PAGE technique. The proteins were transferred to a PVDF membrane and blocked with $5 \%$ milk in TBS/Tween (0.1 M Tris- $\mathrm{HCl}, 0.15 \mathrm{M} \mathrm{NaCl}, 0.1 \%$ Tween 20), immunodetected using goat anti-COL3A1 $\mathrm{Ab}(\mathrm{C}-15)$ at 1:500 dilution and the appropriate HRP-conjugated secondary Ab. The chemiluminescence detection of the separated bands was performed using the enhanced chemical luminescence (ECL) kit and Hyperfilm ECL from Amersham (Piscataway, NJ). To normalize protein loading of the lanes, the membranes were stripped and reblotted with rabbit anti-GADPH Ab (FL-335) at 1:500 dilution, donkey anti-goat HRP-conjugated $\mathrm{Ab}$, and goat anti-rabbit HRP conjugated $\mathrm{Ab}$.

\section{Immunofluorescence analysis}

The cells were cultured on microscopic glass slides and grown to a near-confluent state. Afterwards, the cells were fixed in 4\% PFA in PBS for 10 minutes at room temperature, permeabilized in ice-cold acetone/methanol (1:1) for $10 \mathrm{~min}$ at $-20^{\circ} \mathrm{C}$, rinsed with PBS and blocked in 3\% BSA for 45 minutes. Several primary antibodies were used for detection including COL1A2 (1:50, 1 hour/RT, goat polyclonal anti-human, clone M-19, Santa Cruz Biotechnology), COL3A1 (1:100, 1 hour/RT, goat polyclonal anti-human, clone C-15, Santa Cruz Biotechnology), COL15A1 (1:200, 1 hour/RT, goat polyclonal anti-human, clone N-20, Santa Cruz Biotechnology) and COL21A1 (1:50, 1 hour/RT, goat polyclonal anti-human, clone D-13, Santa Cruz Biotechnology) along with the corresponding green dye labelled secondary anti-goat antibody (MFP488, donkey anti-goat IgG, 1:200, 1 h/RT, MoBiTec). Afterwards, the cells were washed three times with PBS and sealed with DAPI-containing mounting medium. The cells were viewed under a fluorescence microscope (Zeiss Axio-Imager.Z1). The expression of COL1A2, COL3A1, COL15A1 and COL21A1 was analysed using pseudo-colour representations of fluorescence intensity for DAPI at $365 \mathrm{~nm}$ excitation 
and $420 \mathrm{~nm}$ emission wavelengths (blue) and for MFP488 at $470 \mathrm{~nm}$ excitation and $525 \mathrm{~nm}$ emission wavelengths (green).

For the double fluorescence staining, the fixation, blocking and washing steps were conducted as described above. The incubation with first primary antibody ALDH1A1 (1:50, 1 hour/RT, rabbit polyclonal anti-human, clone EP1933Y, Abcam) was then followed by an incubation with the respective red dye labelled secondary anti-rabbit antibody (MFP590, goat anti-rabbit IgG, 1:200, 1 h/RT, MoBiTec). Afterwards, the cells were washed three times with PBS and the second primary antibody was applied, COL3A1 (1:100, 1 hour/RT, goat polyclonal anti-human, clone C-15, Santa Cruz Biotechnology). The cells were then incubated with the respective green dye labelled secondary anti-goat antibody (MFP488, donkey anti-goat IgG, 1:200, 1 h/RT, $\mathrm{MoBiTec})$. Subsequently, the cells were washed three times with PBS and sealed with DAPI-containing mounting medium. The fluorescence intensity was analysed for DAPI at $365 \mathrm{~nm}$ excitation and $420 \mathrm{~nm}$ emission wavelengths (blue), for MFP590 at $550 \mathrm{~nm}$ excitation and $605 \mathrm{~nm}$ emission wavelengths (red) and for MFP488 at $470 \mathrm{~nm}$ excitation and $525 \mathrm{~nm}$ emission wavelengths (green).
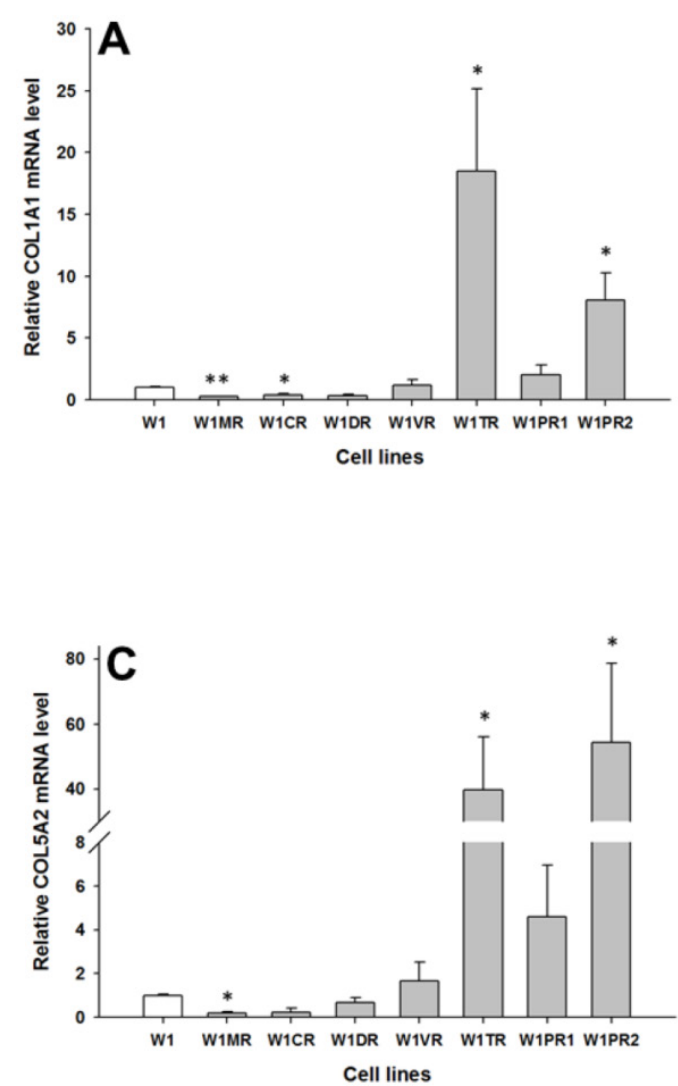

Figure 1. Expression analysis (Q-PCR) of COL1A1 (A), COL3A1 (B), COL5A2 (C) and COL15A1 (D) genes in W1 and its drug resistant sublines. The figure presents relative gene expression of the resistant cell lines (grey bars) with respect to the WI cell line (white bars), which is assigned a value of 1 . Values were considered statistically significant at $p<0.05^{*}, p<0.01 * *, p<0.001^{* * *}$.

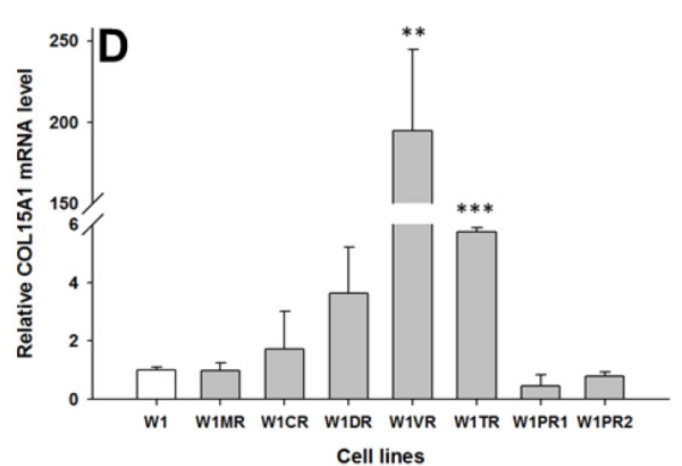

\section{Statistical analysis}

Statistical analysis was performed using Microsoft Excel software. The statistical significance of the differences was determined using Student's $\mathrm{t}$-test and $\mathrm{p}$ values of 0.05 or less were considered statistically significant.

\section{Results}

\section{Gene expression analysis in drug resistant ovarian cancer cell lines}

\section{W1}

To determine whether the development of drug-resistant variants of W1 cells is associated with increased expression of collagen genes, the expression levels of COL1A1, COL3A1, COL5A2 and COL15A1 were assessed. The transcript level of COL1A1 was significantly higher in the TOP resistant cell line W1TR $(p<0.05)$ and one of the PAC resistant cell lines (W1PR2) $(p<0.05)$ and was significantly lower in the MTX resistant W1MR $(\mathrm{p}<0.01)$ and CIS resistant W1CR $(p<0.05)$ cell lines (Fig. 1A). The COL3A1 transcript level was significantly higher in the TOP resistant W1TR $(p<0.01)$ and both the PAC resistant, W1PR1 $(\mathrm{p}<0.05)$ and W1PR2 $(\mathrm{p}<0.01)$ cell lines

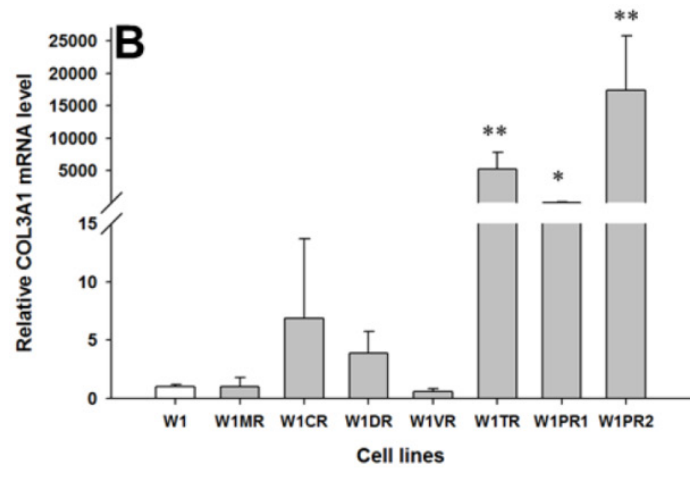


(Fig. 1B). However, the expression of COL3A1 was variable in these cell lines. We observed approximately twenty fold higher transcript levels in the W1PR1 cells in comparison to control. Expression in the W1TR cells increased over 5000-fold and in the W1PR2 cells over 15000-fold in comparison to the W1 cell line. The COL5A2 transcript level was significantly higher in the TOP resistant W1TR cell line $(p<0.05)$ and the PAC resistant W1PR2 cell line $(p<0.05)$. In contrast, significantly lower level of COL5A2 were observed in the MTX resistant W1MR cell line $(p<0.05)$ (Fig. 1C). COL15A1 expression was significantly higher in the VIN resistant W1VR $(\mathrm{p}<$ $0.01)$ and the TOP resistant W1TR $(p<0.001)$ cell lines
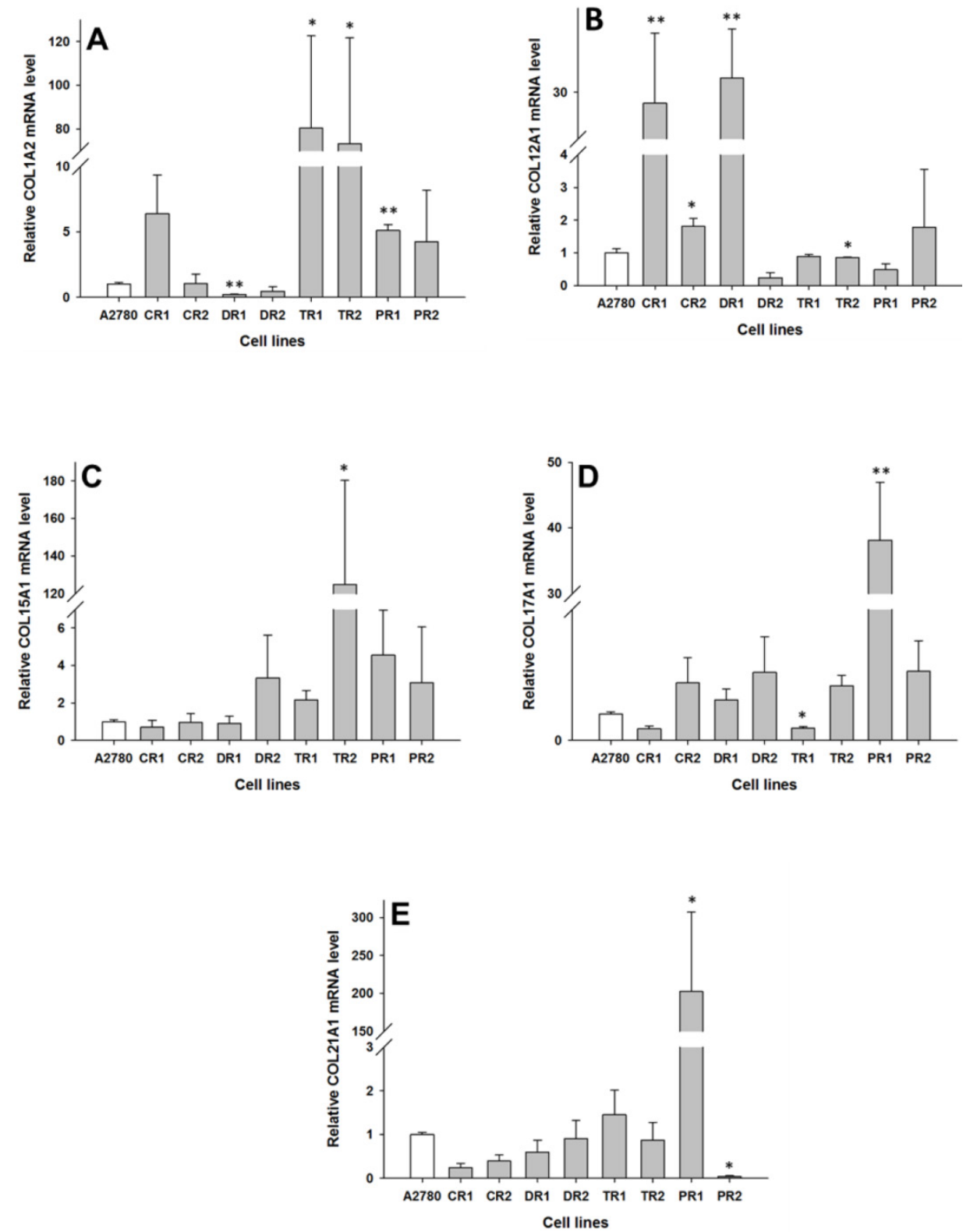

Figure 2. Expression analysis (Q-PCR) of COL1A2 (A), COL12A1 (B), COL15A1 (C), COL15A1 (D) and COL21A1 (E) genes in A2780 and its drug resistant sublines. The figure presents the relative gene expression of the resistant cell lines (grey bars) with respect to the A2780 cell line (white bars), which is assigned a value of 1 . Values were considered statistically significant at $\mathrm{p}<0.05^{*}, \mathrm{p}<0.01 * *$.
(Fig. 1D). However, the W1TR and the W1VR cell lines expressed different levels of COL15A1. Expression of COL15A1 in the W1TR cell line increased only six-fold in comparison to the nearly 200-fold increase in the W1VR cell line.

\section{A2780}

In the drug resistant sublines of the A2780 ovarian cancer cell line, we observed changes in expression of the following five collagen genes: COL1A2, COL12A1, COL15A1, COL17A1 and COL21A1. The transcript level of COL1A2 was significantly higher in both the TOP resistant cell lines A2780TR1 and A2780TR2 ( $p<0.05)$, and one PAC resistant cell line, A2780PR1 $(\mathrm{p}<0.01)$. However, the expression of COL1A2 in the TOP resistant cell lines was much higher than in the PAC resistant cell line. In contrast, the gene expression of COL1A2 in the DOX resistant A2780DR1 cell line was significantly lower than in the A2780 cell line $(\mathrm{p}<$ 0.01 ), as shown in Fig. 2A. The expression of COL12A1 was significantly higher in both the CIS resistant cell lines A2780CR1 $(p<0.01)$ and A2780CR2 ( $p<0.05)$ as well as the DOX resistant cell line A2780DR1 ( $p$ < $0.01)$. In contrast, in the TOP resistant A2780TR2 cell line, the COL12A1 expression was slightly lower $(\mathrm{p}<0.05)$, as shown in Fig. 2B. It is important to note that the expression of COL12A1 in the A2780CR2 cell line was much lower than its expression in the A2780CR1 and A2780DR1 cell lines. The COL15A1 transcript level was significantly higher $(p<0.05)$ only in the TOP resistant A2780TR2 cell line (Fig. 2C). The COL17A1 transcript level was significantly higher in the PAC resistant cell line A2780PR1 ( $\mathrm{p}<0.05)$ and significantly lower in the TOP resistant A2780TR1 cell 
line $(\mathrm{p}<0.05)$, as shown in Fig. 2D. The expression of COL21A1 was significantly higher in the A2780PR1 cell line, which is resistant to PAC treatment $(p<$ 0.05). In contrast, the second PAC resistant cell line A2780PR2 was characterized by the significantly decreased expression of COL21A1 ( $p<0.05)$, as shown in Fig. 2E.

\section{SKOV-3}

The expression of the same genes present in $\mathrm{W} 1$ and A2780 cell lines were analysed in the drug resistant sublines of SKOV-3 ovarian cancer cell lines. Between the parental and the drug resistant cell lines, we observed differences in the expression of the following four COL genes: COL1A1, COL3A1, COL15A1 and COL17A1. COL1A1 expression was significantly increased only in one TOP resistant SKOV-3TR1 cell line ( $<<0.05)$, as shown in Fig. 3A. In contrast, the expression of COL3A1 was significantly decreased in one of the CIS resistant SKOV-3CR1 cell lines $(\mathrm{p}<0.05)$, as shown in Fig. 3B. We observed a significantly higher expression of COL15A1 in both the CIS resistant SKOV-3CR1 and SKOV-3CR2 cell lines $(\mathrm{p}<0.01)$ and both the TOP resistant SKOV-3TR1 and SKOV-3TR2 cell lines $(\mathrm{p}<0.05)$ as


Figure 3. Expression analysis (Q-PCR) of COL1Al (A), COL3A1 (B), COL15Al (C) and COL17Al (D) genes in SKOV-3 and its drug resistant sublines. The figure presents the relative gene expression of resistant cell lines (grey bars) with respect to the SKOV-3 cell line (white bars), which is assigned a value of 1 . Values were considered statistically significant at $\mathrm{p}<0.05^{*}$, $p<0.01 * *$. shown in Fig. 3C. However, COL15A1 expression in the SKOV-3TR1 cell line was much higher than in the other cell lines with increased expression. COL17A1 expression was also significantly increased in both the CIS resistant cell lines (SKOV3-CR1, $\mathrm{p}<0.05$ and SKOV3-CR2, $\mathrm{p}<0.01$ ) and both the TOP resistant cell lines (SKOV-3TR1, $\mathrm{p}<0.01$ and SKOV-3TR2, $\mathrm{p}<0.05$ ), as shown in Fig. 3D.

\section{Immunofluorescence of COL proteins expressed in resistant cell lines}

To confirm the expression of collagens at the protein level, we used the immunofluorescence assay. In $\mathrm{W} 1$ sublines, the COL genes that were highly expressed were COL3A1 and COL15A1. The immunofluorescence analysis validated the transcript expression results. We observed an increased expression of COL3A1 in the W1 sublines resistant to PAC and TOP (Fig. 4A). Similarly, the expression of COL15A1 was observed in cell lines resistant to VIN and TOP (Fig. $4 \mathrm{~B}$ ). In the drug resistant sublines of A2780, we observed increased expression of COL1A2, COL15A1 and COL21A1. The expression of these genes was also confirmed at the protein level. We observed the expression of COL1A2 in both the cell lines resistant to TOP and in one of the cell lines (A2780PR1) resistant to PAC (Fig. 5 A). The A2780TR2 cell line was also characterized by the expression of COL15A1 (Fig. 5B), and the A2780PR1 cell line was characterized by the expression of COL21A1 (Fig. 5C). The most abundantly expressed COL in SKOV-3 resistant sublines was COL15A1, and we also confirmed its expression at the protein level in all the resistant sublines (Fig. 6). 


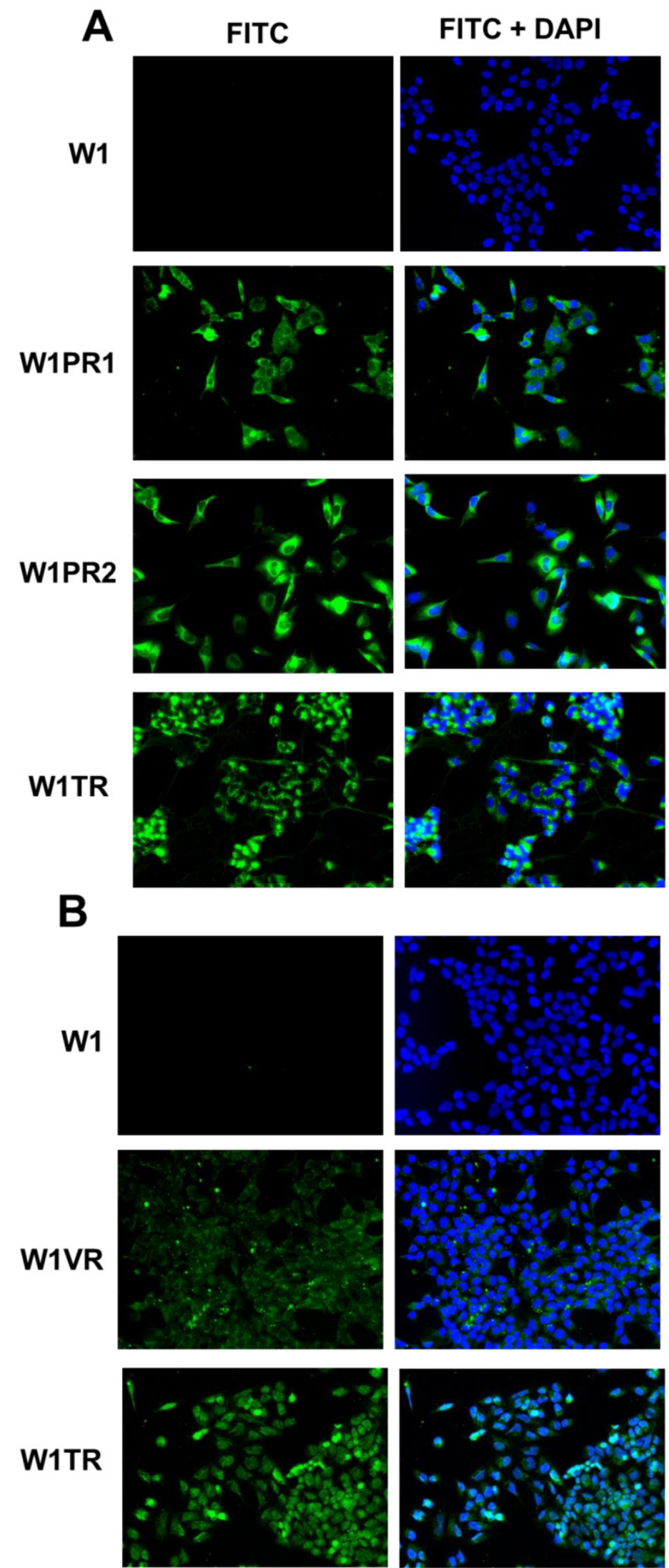

Figure 4. Immunofluorescence visualization of COL3A1 expression (A) in WI, WIPRI, WIPR2 and WITR cell lines. Immunofluorescence visualization of COL15A1 (B) expression in W1, WIVR and WITR cell lines. COL3A1 was detected using the anti-COL3A1 antibody and an MFP488-conjugated secondary antibody (green). Similarly, COL15A1 was detected using the anti-COL15A1 antibody and an MFP488-conjugated secondary antibody (green). To visualize the cell nuclei, the cells were mounted with a DAPI-containing mounting medium (blue). 


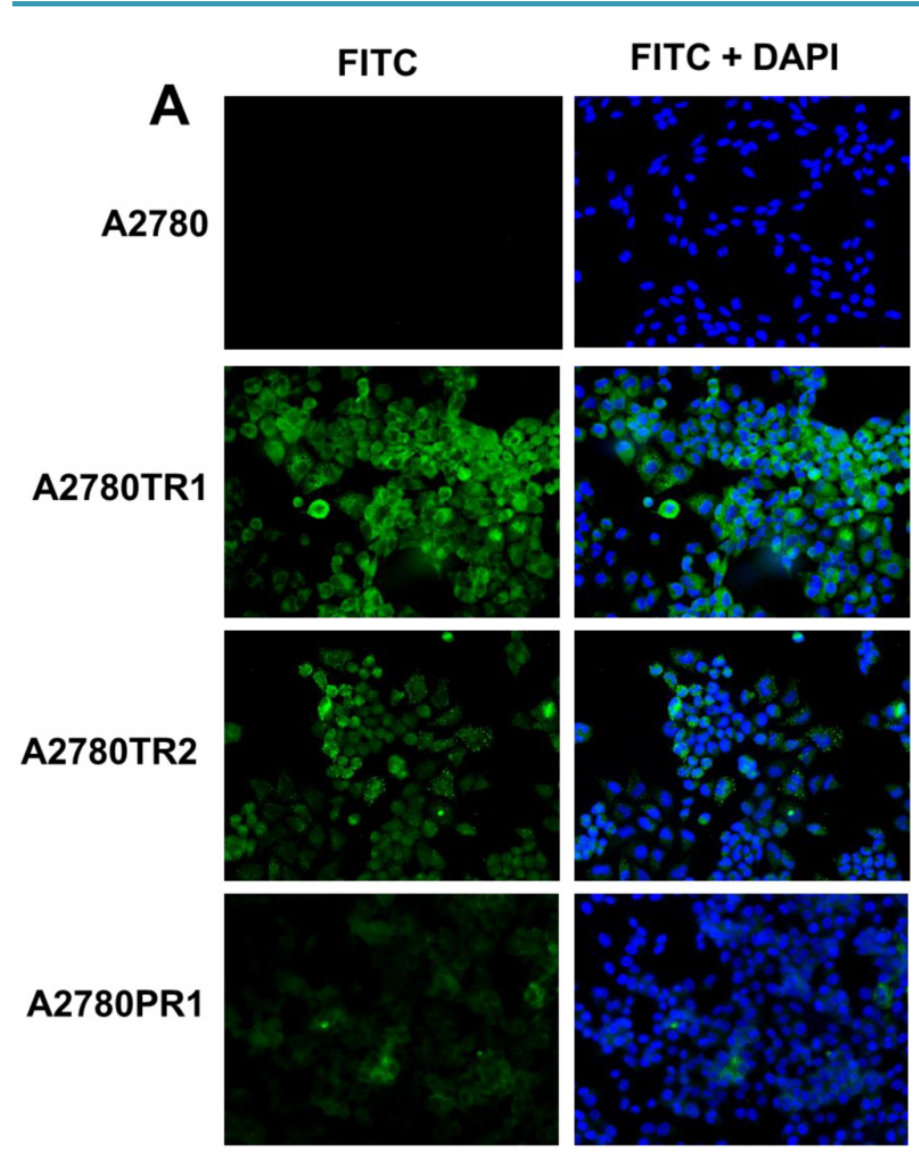

FITC


A2780TR2
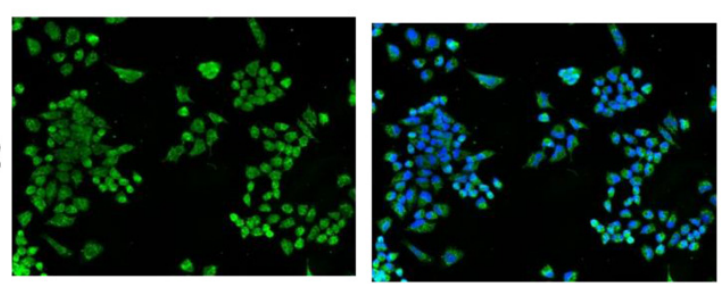

C

A2780
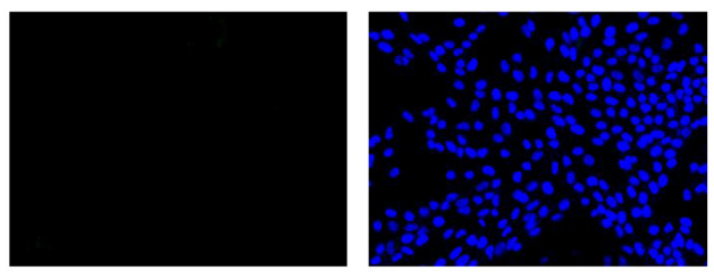

Figure 5. Immunofluorescence visualization of COL1A2 (A) expression in A2780, A2780TR1, A2780TR2 and A2780PR1 cell lines; COL15A1 expression in $A 2780$ and $A 2780 T R 2$ cell lines (B); and COL21A1 expression in $A 2780$ and $A 2780 P R 1$ cell lines (C). COL1A2 was detected using the anti-COL1A2 antibody and an MFP488-conjugated secondary antibody (green). COL15Al was detected using the anti-COL15Al antibody and an MFP488-conjugated secondary antibody (green). Similarly, COL21A1 was detected using the anti-COL15Al antibody and an MFP488-conjugated secondary antibody (green). To visualize the cell nuclei, the cells were mounted with a DAPI-containing mounting medium (blue).

A2780PR1
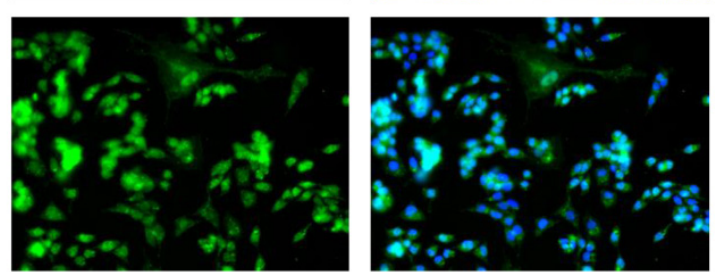


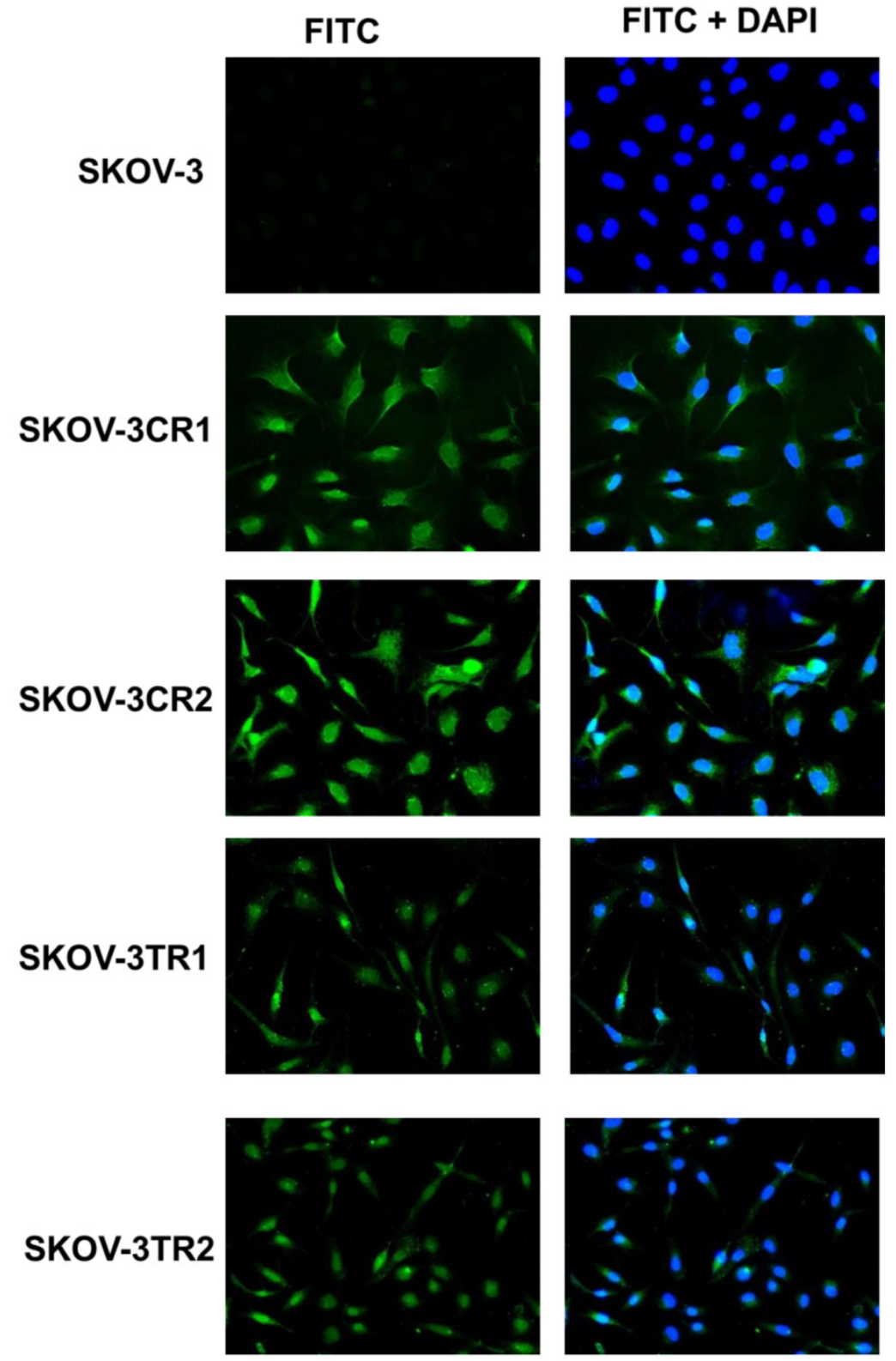

Figure 6. Immunofluorescence visualization of COL15A1 expression in SKOV-3, SKOV-3CR1, SKOV-3CR2, SKOV-3TR1 and SKOV-3TR2 cell lines. COL15A1 was detected using the anti-COL15Al antibody and an MFP488-conjugated secondary antibody (green). To visualize the cell nuclei, the cells were mounted with a DAPI-containing mounting medium (blue).

\section{Western blot analysis of COL3A1}

Among all the analysed COL genes, the expression of COL3A1 was the highest. In the TOP resistant W1TR cell line and in the PAC resistant W1PR2 cell line, we observed extremely high levels of the COL3A1 transcript. To be certain that this is also true at the protein level, we confirmed its expression using Western blot analysis. The Western blot analysis validated the significant expression of COL3A1 in the cell lines resistant to TOP and PAC (Fig. 7). In W1TR W1PR1 and W1PR2 cell lines we observed bound corresponding to $140 \mathrm{kD}$. In W1PR2 cell line we observed additional bound corresponding to smaller isoform of COL3A1 with molecular mass of $110 \mathrm{kD}$.

\section{Extracellular expression of COL3A1}

In the W1TR cell line resistant to TOP, we observed the expression of COL3A1 not only inside the cells but also in the extracellular milieu. The extracellular COL structure was similar to that of a spider's web (Fig. 8).

\section{Co-expression of COL3Al and ALDHIAI}

The double immunofluorescence assay showed the co-expression of COL3A1 in the W1TR cell line with the marker ALDH1A1 for CSCs. The cells expressing ALDH1A1 expressed much higher levels of COL3A1 than the cells that did not express ALDH1A1. 


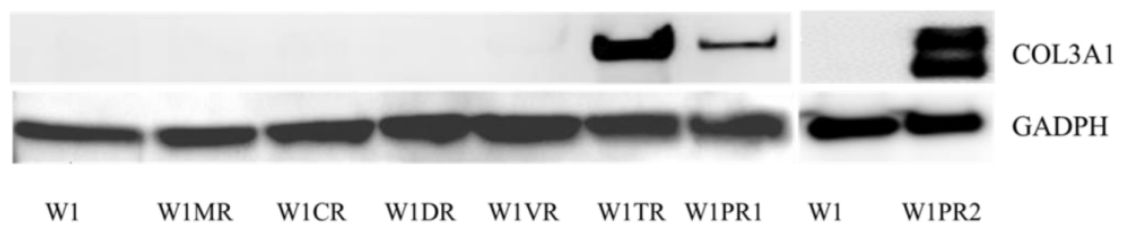

Figure 7. COL3A1 protein expression in $\mathrm{W} 1$ and drug-resistant cell lines. The cellular proteins were separated using 7\% PAGE, transferred to PVDF, and the membrane was immunoblotted with either primary Ab or HRP-conjugated secondary Ab. As a loading control, a primary anti-GADPH Ab was used.
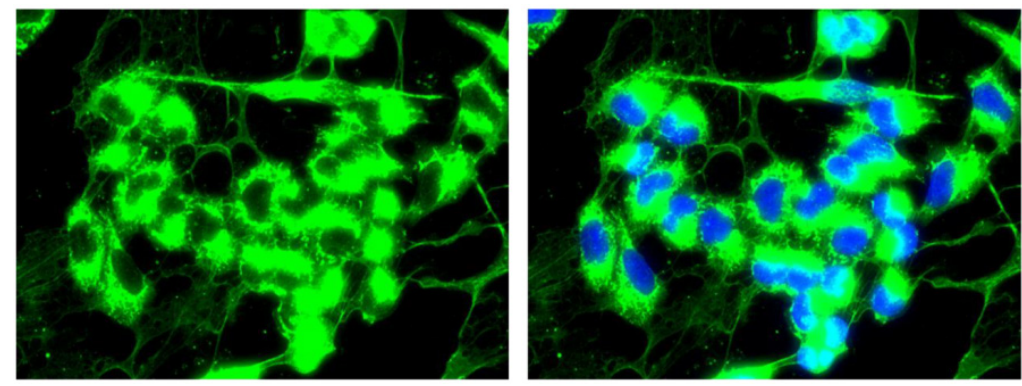

Figure 8. Immunofluorescence visualization of intracellular and extracellular COL3AI expression in the WITR cell line. COL3AI was detected using the anti-COL3Al antibody and an MFP488-conjugated secondary antibody (green). To visualize the cell nuclei, the cells were mounted with a DAPI-containing mounting medium (blue).
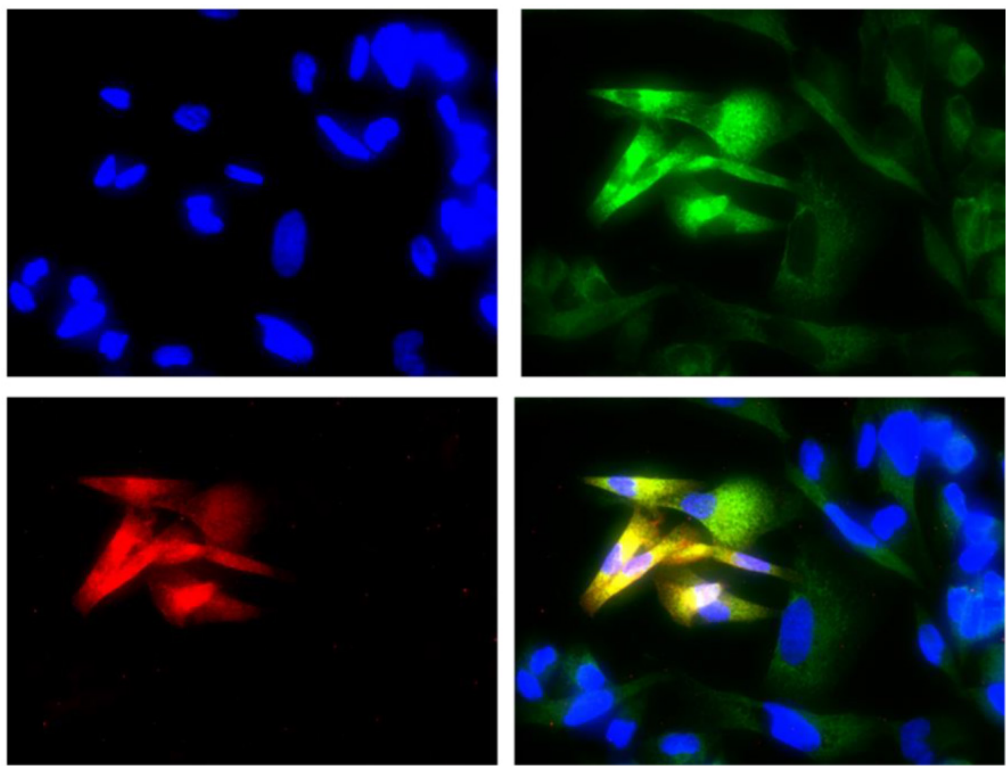

Figure 9. Immunofluorescence visualization of COL3AI and ALDHIAl co-expression in the WITR cell line. COL3AI was detected using the anti-COL3AI antibody and an MFP488-conjugated secondary antibody (green). ALDHIA1 was detected using the anti-ALDHIA1 antibody and an MFP590-conjugated secondary antibody (red). To visualize the cell nuclei, the cells were mounted with a DAPI-containing mounting medium (blue).

\section{Discussion}

Drug resistance is the main problem in the treatment of cancer patients. Some cancers are intrinsically resistant to chemotherapy, while others develop drug resistance during treatment [30]. During the last few decades, the basic model for investigation of drug resistance development in cancer was a model that compared the gene expression in drug sensitive and drug resistant pairs of cell lines. These models resulted in significant progress in our understanding of the mechanisms of drug resistance of cancer cells and led to improvements in the treatment of cancer. However, this progress is still limited, and in most cases, cancer eventually results in patient death. One of the reasons for the limited progress is that most researchers concentrate their attention only on the cellular mechanisms of drug resistance [31]. Whereas, from the clinical point of view, other mechanisms of drug resistance that are specific to the microenvironment of cancer cells in the tumour, and the architecture of the tumour as an organ-like structure can be more significant than the cellular mechanisms $[12,26]$. Tissue specific mechanisms of 
drug resistance are related, among other mechanisms, to the expression of ECM molecules, including collagens $[12,16,20,26,27]$. However, the expression of COL genes is observed both in tumour tissues as well as in drug resistant cancer cell lines [21-24, 32]. This observation indicates that the expression of collagens can be important in cancer drug resistance at both the tissue and cellular levels. In contrast to other papers, this paper describes the expression of COL at both the transcript level as well as the protein level and presents data that shows cells growing as monolayers can expresses extracellular collagen. In our study, we used ovarian cancer drug resistant cell lines that were developed from drug sensitive cell lines by exposing them to drugs that are used in the treatment of ovarian cancer. Most of these cell lines were previously characterized based on their expression of drug transporters [33-36] and drug cross-reactivity [36]. For analysis, we selected collagen genes selected using microarray analysis data from W1 [24] and A2780 [23] cell lines. In the SKOV-3 cell lines, we analysed all the COL genes indicated in both the microarray analyses. In all the investigated cell lines, the expression of COL genes was investigated by Q-PCR. The expression of highly expressed collagens was also confirmed by immunofluorescence and Western blot in the case of COL3A1.

We can divide the investigated collagen genes into three groups based on the level of expression in the investigated cell lines as follows: 1 . genes with less than a 50-fold increase in expression compared to the control, which include COL1A1, COL5A2, COL12A1 and COL17A1; 2. genes with more than a 50-fold increase in expression compared to the control, which include COL1A2, COL15A1 and COL21A1; and 3. a gene with a very high expression level, COL3A1.

On the basis of their polymerization patterns, collagens are divided into different classes. Among the investigated collagens, type I, type II, type III and type V comprise a fibrillar class [37,38]. Type XII and type XXI collagens belong to the FACIT (fibril associated collagens with interrupted triple helices) class [38, 39]. Type XV collagen belongs to the multiplexin (multiple triple helix domains with interruptions) class [38, 40], and type XVII collagen belongs to the MACIT (membrane associated collagens with interrupted triple helices) class [38].

Among the investigated collagens, types I and V exist as heterotrimers. Mature type I collagen is heterotrimeric and consists of two alfa I chains and one alfa II chain [37, 38]. Mature type V collagen consists of two alfa I and one alfa II chains or one alfa I, one alfa II and one alfa III chain [38]. Expression of COL1A1 was increased in two cell lines resistant to TOP, W1TR and SKOV-3TR2. However, in both the cell lines expressing COL1A1, we did not observe any changes in the COL1A2 expression. In contrast, we observed changes in the expression of COL1A2 in two other TOP resistance cell lines, A2780TR1 and A2780TR2, and, to a smaller degree, in the A2780PR1 cell line, which is resistant to PAC. Similarly, the expression of COL5A2 was detected in W1TR and W1TPR2 cell lines where there was an absence of COL5A1 and/or COL5A3 expression. The formation of procollagen triple helix takes place in the rough endoplasmic reticulum, and these procollagen molecules are secreted from the cells through secretory vesicles. The final formation of collagen fibrils takes place in the extracellular matrix [38]. Because type I and V collagens are heterotrimeric molecules the question is what is a role of COL1A1 expression in the absence of COL1A2 and opposite and the role of COL5A2 expression in the absence of COL5A1 or COL5A3? It could be hypothesized that, in immature forms, these chains are not secreted from the cells. Thus, can they remain in the cells and play a special role in drug resistance? It is also possible that cancer cells can form atypical forms of collagens I or $\mathrm{V}$ composed of only one type of chain. These two possibilities however, require additional, more detailed studies. Thus far, the expression of COL1A1 and COL1A2 has been noted in gastric cancer and was positively correlated with the degree of invasion, metastasis and advanced stages [41]. The expression of COL5A2 was upregulated in colon carcinoma [42] and in human endometrial cancer, where it was associated with the development and progression of cancer [43]. COL5A2 expression also increased during the progression of ductal carcinoma in situ (DCIS) to invasive ductal carcinoma (IDC) [44].

The most abundantly expressed collagen in our cell lines was COL3A1. We observed an increased expression in the W1PR1 cell line resistant to PAC as well as extremely high expression levels in the W1TR cell line resistant to TOP and in the W1PR2 cell line resistant to PAC. Furthermore, we were able to confirm its expression using Western blotting and showed using immunofluorescence that it is secreted from cells as a mature collagen molecule and forms a structure similar to a spider's web in the W1TR cell line. To our knowledge, this is the first study that has shown the presence of extracellular collagen in a cell culture grown as a monolayer. It is also very important to note that, among all the upregulated genes in the W1TR cell line, the upregulation of COL3A1 was the highest (unpublished microarray data). The extremely high expression levels suggest that the protein plays an important role in these cells. This indicates that COL3A1 is really involved in TOP and PAC resistances. Expression of COL3A1 was also 
noted in solid tumours. It was associated with breast cancer development and progression [45] and the resistance of ovarian cancer to CIS treatment [46].

Collagens type XII and XXI, which are encoded by COL12A1 and COL21A1 genes respectively, belong to the FACIT collagen family and are expressed in tissues containing type I collagen and are located on the surface of fibrils. COL XII also interacts with decorin and glycosaminoglycans, and COL XXI is responsible for maintaining the three-dimensional structure of dense connective tissue [38, 39]. We observed an increase in the COL12A1 expression in both the CIS resistant A2780 cell lines, although at very different levels, as well as in one of the DOX resistant A2780 cell lines. The increased expression of COL12A1 was also observed in PAC and DOX resistant variants of the breast cancer cell line MCF-7 [21]. In solid tumours, the expression of COL12A1 was detected during the progression of ductal DCIS to IDC [44], as well as in colorectal cancer [47], and thus seems to be a marker of this cancer [47, 48]. Furthermore, COL12A1 seems to play a role in the drug resistance of cancer cells and in tumour progression. However, the expression of COL12A1 appears to be a non-specific response to drug treatment because the two A2780 cell lines that are resistant to the same cytostatic drug have very different levels of COL12A1 expression.

We observed an increase in the expression of COL21A1 in A2780PR1 cell line resistant to PAC. To our knowledge, the expression of this COL gene has not been reported in cancers or cancer cell lines by other researchers so far. Therefore, the role of COL21A in drug resistance requires further investigation.

COL15A1, a member of the multiplexin family, is the most abundant COL expressed in the basement membrane zones [40]. Its expression has been associated with the suppression of tumours in human cervical carcinoma in vivo [49] and in a mouse model [50]. In contrast, we observed the upregulation of COL15A1 in the W1 drug resistant cell lines resistant to VIN and TOP. However, its expression in VIN resistant cell lines was much higher. The expression of COL15A1 was also significantly higher in the A2780TR2 cell line and in all the drug resistance SKOV-3 cell lines as well as had very high expression levels in the SKOV-3TR1 cell line. Because an increased expression of COL15A1 was observed in all drug resistant SKOV-3 cell lines, this suggests that COL15A1 is a non-specific mechanism of drug resistance in these cell lines. In the other cell lines, COL15A1 expression is associated with TOP or VIN resistances. Upregulation of COL15A1 in three out of the five TOP resistant cell lines suggests that its expression can be associated with TOP resistance. This observation, however, requires additional studies.

COL17A1, a structural component of hemidesmosomes, is a transmembrane protein expressed in epithelial cells and plays an important role in maintaining the link between the intracellular and extracellular structural elements [51]. This type of a transmembrane protein is not only a matrix component, but it can also function as a cell surface receptor. Its expression was noted in malignant but not in benign melanocytic tumours, and it can be a molecular target that induces apoptosis [52]. Upregulation of COL17A1 was also reported in squamous cell carcinomas (SCCs) and in malignant cell lines [53], but its relationship to drug resistance has not been reported so far. Here, we observe a significant increase in the expression of COL17A1 in the PAC resistant A2780PR1 cell line and in both CIS and TOP resistant SKOV-3 cell lines. The exact role of this increased expression is difficult to explain at the moment. The expression of COL17A1 in all the SKOV-3 drug resistance cell lines suggests that it can have a non-specific response to cytostatic drug treatment. If COL17A1 can behave as a receptor, it is possible that its increased expression can initiate signals that help the cells survive during chemotherapy. On the other hand, because anti-COL17A1 Ab induced apoptosis in melanoma [51], it is also possible that COL17A1 can be a molecular target in our cell lines. This observation, however, requires additional studies.

It appears that the overexpression of collagens can protect cancer cells against chemotherapeutic agents in different ways. In many tumours resistant to drugs, the time needed for the penetration of the collagen network is lengthened, which can result in drug resistance by preventing the penetration of drug [16]. In contrast to normal tissues where collagen is organized as thin, long wavy fibrils parallel to the epithelial boundary, collagen fibrils in tumour stroma are thicker and shorter [54]. In EOC, collagen tracts that are perpendicular to the epithelial boundary have been observed [55]. It has been shown that ECM containing a large amount of collagen increases the invasiveness and the progression of tumours [56]. The expression of nearly all the collagens investigated in this paper was related to tumour progression and increased metastasis. Because metastasis and invasive tumours are usually more resistant to chemotherapy, this suggests that expression of the COL gene can be related to chemotherapy resistance. Among the COL genes upregulated in this study, the expression of COL3A1 was observed in ovarian cancer and was shown to be related to CIS resistance [46]. This 
however, does not mean that other COLs upregulated in our study cannot be upregulated in ovarian or other tumours. Their expression was probably kept in check in solid tumours. Because we show increased expression of this gene in ovarian cancer cell lines resistant to cytostatics used in the treatment of this cancer, it would be very interesting to compare their expression in primary tumours and metastasis as well as in primary tumours without and after neoadjuvant chemotherapy. This type of study also needs to be conducted in animal models of ovarian cancer, especially to study the resistance to TOP and DOX, which are drugs used in the second line of chemotherapy, because after the second line of chemotherapy, patients do not undergo surgery. However, the expression of other COL genes was described in ovarian cancer in relation to tumour progression, metastasis and chemotherapy resistance. Jazaeri et al. observed increased levels of COL6A1 in ovarian tumours resistant to Carboplatin/PAC based chemotherapy [57]. Increased expression levels of COL6A3 were observed by Sherman-Baust et al. in different histological types of ovarian cancer, and the COL6A3 expression levels correlated with the grades of the tumours [22]. The expression of COL11A1, COL5A1 and COL6A2 were associated with poor overall survival (OS) in patients with high-grade serous ovarian cancer. Furthermore, the expression of COL11A1 was associated with disease progression and the highest COL11A1 expression occurred in recurrent metastases [58]. The aforementioned examples indicate that the expression of different collagens is associated with ovarian cancer progression and drug resistance in vivo. This can result from the fact that dense and tortuous extracellular matrix can limit drug delivery [12], and some cytostatic drugs can bind to cellular macromolecules that limit their availability to the tumour $[15,59]$.

These mechanisms also seem to be true in tumour tissue. However, the expression of COL genes has been studied in drug resistance cancer cell lines only at the RNA level [21, 22]. To our knowledge, this is the first paper showing that cells growing in culture as monolayers are able to secrete extracellular collagen. Here, we present the extracellular expression of only COL3A1 because it was the most abundant collagen in the investigated cell lines. However, these results suggest that other collagens can also be secreted from cells that are grown as monolayers. Thus, the question is, what is the role of this extracellular collagen in drug resistance? We hypothesize three possibilities. The first being that the extracellular and intracellular collagens are able to bind to drug molecules and, in that way, limits their availability to cancer cells. This mechanism of drug resistance is applicable in the cases of TOP and PAC resistant cell lines. In our study, all fibrillar collagens (COL1A1, COL1A2, COL3A1 and COL5A2) were upregulated only in the TOP and PAC resistant cell lines, which can indicate that the structure of fibrillar collagens can be related to TOP and PAC resistance. It is possible that the structural organization of fibrillar collagens is able to bind the TOP and PAC molecules and limit their availability to cancer cells. This, however, requires additional and more detailed studies.

From literature data we know that expression of extracellular collagens can limit drug diffusion in tumor tissue [12, 15-19]. It is also possible that expression of COL genes in our cell lines can also limit drug diffusion. However these kinds of study require different model of study like cells growing in 3D cell culture condition as a sphere in the hanging drops [60].

The other role of extracellular collagen is in cell adhesion-mediated drug resistance (CAM-DR) [61]. This type of drug resistance was observed both in vivo and in vitro. It is known that cells can interact with their microenvironment through surface receptors such as integrins, and this interaction leads to the inhibition of drug induced apoptosis. In a SCLC study, it was observed that the interaction of $\beta 1$-integrin with ECM leads to resistance of the cells to DOX and melphalan treatments [28]. This type of drug resistance was also observed in vitro. It has been shown that A2780 ovarian cancer cell lines resistant to CIS expressed increased levels of COL6A3. Furthermore, when the authors cultured a drug sensitive A2780 cell line on COL6A3 coated dishes, they observed that the cell line became resistant to CIS [22]. This result was probably due to the interaction of cell receptors through direct or indirect binding to collagen. Similar results were observed when the cells were grown in 3D cell culture conditions. In such conditions, cells grow on the surface of various gels including collagens and are usually more resistant to the cytostatic drugs than the same cells growing as monolayers in 2D cell culture conditions [62]. The adhesion of pancreatic cancer cell lines MIA PaCa-2, PANC-1, and Capan-1 to components of ECM, such as fibronectin $(\mathrm{FN})$, laminin (LN), COL I or COL IV, protects these cell against CIS, 5-fluorouracil (5-FU) and DOX [63]. Similar results were observed in the breast cancer cell line MDA-MB-231, where adhesion of these cells to fibronectin or type I collagen inhibited PAC induced apoptosis [64].

Thus, it is clear that ECM components induce CDM-DR in cancer cells. Taking into consideration that a very large amount of COL3A1 is expressed in 
the W1TR cell line and that COL3A1 is secreted from these cells, we can hypothesize that this extracellular collagen can protect cancer cells against TOP through CAM-DR. Cancer cells expressing extracellular collagen can also induce drug resistance in surrounding cells not expressing collagen through CAM-DR both in vitro and in tumour tissue.

Morin suggested that cancer cells expressing high levels of ECM components preferentially survive chemotherapy because these cells are more resistant to apoptosis and drug treatment [27]. These cells are further responsible for clonal expansion and tumour progression. This model of drug resistance in the tumour is very similar to the CSC model of drug resistance development [8]. To verify if cells expressing high levels of extracellular COL3A1 have the same features as CSCs, we studied the expression of ALDH1A1 in the W1TR cell line. We detected the expression of ALDH1A1 in some W1TR cells, and, even more interesting, the cells expressing ALDH1A1 expressed a much higher level of COL3A1 than the other cells. This observation suggests that ALDH1A1+ cancer stem like cells are the main cells responsible for COL3A1 production in these cell lines. It is possible that COL3A1 expressed and secreted from ALDH1 $11^{+}$cells can induce resistance in surrounding cells through inhibition of apoptosis. Because the expression of COL3A1 was observed in ovarian cancer and was associated with CIS resistance [46] and because the presence of ALDH1A1 cells was also observed in ovarian cancer [9] and ovarian cancer cell lines [10] and was associated with CIS and PAC resistance in cell lines [10], it is possible that CSCs are responsible for the development of drug resistance not only by overexpressing drug transporters but also by overexpressing ECM components such as collagens and CAM-DR. These observations, however, require additional and more detailed studies.

In contrast to our previous study in which we observed the drug specific expression of drug transporters from the $A B C$ family [33-36], the expression of different COL genes is, in most cases, not related to the type of cytostatic drug used both in vivo and in vitro. Thus, COL expression appears to be a complementary mechanism of cancer drug resistance at both the cellular and cancer tissue levels. However, we should keep in mind that in contrast to the study concerning the role of drug transporters from the $\mathrm{ABC}$ family in drug resistance, studies concerning COL expression in drug resistance are very limited. In the future, it is possible that researchers will be able to identify more specific roles of the various collagens involved in the drug resistance of cancers.

\section{Summary}

In summary, these results present the differences in the expression of several genes encoding different collagen molecules in ovarian cancer cell lines resistant to various cytostatic drugs. Our results indicate that COL proteins may be implicated in drug resistance. For the first time, we have shown that cells growing in monolayers can produce extracellular COL3A1. This observation suggests that CAM-DR can also play a role in cells growing as monolayers. The cells mainly responsible for the production of extracellular COL3A1 seem to be ALDH1A1 positive cells. Correlations between the cytostatic drugs and the expression of various COL molecules have not been observed. However, the expression of fibrillar collagens was found only in cell lines resistant to TOP and PAC, suggesting that fibrillar collagen can play an important role in the cells' resistance to these drugs. The importance of investigating COL gene expression in drug resistance requires further investigation and should be confirmed in other ovarian cancer cell lines, in clinical specimens and in animal models of ovarian cancer.

\section{Acknowledgement}

This study was supported by grant No. 2014/13/B/NZ5/00334 from the National Science Centre and grant No. 502-14-02229373-09711 from Poznan University of Medical Sciences.

\section{Conflicts of interest}

We have no conflicts of interest regarding employment, consultancies, stock ownership, honoraria, paid expert testimony, patent applications/registrations, and grants or other sources of funding.

\section{References}

1. Garcia M, Jemal A, Ward EM, et al. Global cancer facts \& figures. Atlanta, USA: American Cancer Society; 2007.

2. Kurman RJ (ed): Blaustein's Pathology of the Female Genital Tract. 5th edition. New York, USA: Springer; 2002.

3. Hennessy BT, Coleman RL, Markman M. Ovarian cancer. Lancet 2009; 374: 1371-1382.

4. Parmar MK, Ledermann AJ, Colombo $\mathrm{N}$ et al. Paclitaxel plus platinum-based chemotherapy versus conventional platinum-based chemotherapy in women with relapsed ovarian cancer: the ICON4/AGO-OVAR-2.2 trial. Lancet. 2003; 361: 2099-2106.

5. Pujade-Lauraine E, Mahner S, Kaern J, et al. A randomized, phase III study of carboplatin and pegylated liposomal doxorubicin versus carboplatin and paclitaxel in relapsed platinum-sensitive ovarian cancer (OC): CALYPSO study of the Gynecologic Cancer Intergroup (GCIG). J Clin Oncol. 2009; 27 (supp. 18):5509.

6. Sehouli J, Stengel D,Oskay-Oezcelik G et al. Nonplatinum topotecan combinations versus topotecan alone for recurrent ovarian cancer: results of a phase III study of the North-Eastern German Society of Gynecological Oncology Ovarian Cancer Study Group. J Clin Oncol. 2008; 26: 3176-3182.

7. Leonard GD, Fojo $\mathrm{T}$ and Bates SE. The role of $\mathrm{ABC}$ transporters in clinical practice. Oncologist. 2003; 8: 411-424.

8. Januchowski R, Wojtowicz K, Zabel M. The role of aldehyde dehydrogenase (ALDH) in cancer drug resistance. Biomed Pharmacother. 2013; 67: 669-680. 
9. Wang YC, Yo YT, Lee HY, et al. ALDH1-bright epithelial ovarian cancer cells are associated with CD44 expression, drug resistance, and poor clinical outcome. Am J Pathol. 2012; 180: 159-169.

10. Landen CN Jr, Goodman B, Katre AA, et al. Targeting aldehyde dehydrogenase cancer stem cells in ovarian cancer. Mol Cancer Ther. 2010 ; 9 : 3186-3199.

11. Jain RK. Determinants of tumor blood flow: a review. Cancer Res. 1988; 48: 2641-2658.

12. Chauhan VP, Stylianopoulos $\mathrm{T}$, Boucher $\mathrm{Y}$, et al. Delivery of molecular and nanoscale medicine to tumors: transport barriers and strategies. Annu Rev Chem Biomol Eng. 2011; 2: 281-298.

13. Tannock IF, Lee CM, Tunggal JK, et al. Limited penetration of anticancer drugs through tumor tissue: a potential cause of resistance of solid tumors to chemotherapy. Clin Cancer Res. 2002; 8: 878-884.

14. Tunggal JK, Cowan DS, Shaikh H, et al. Penetration of anticancer drugs through solid tissue: a factor that limits the effectiveness of chemotherapy for solid tumors. Clin Cancer Res. 1999; 5: 1583-1586.

15. Di Paolo A, Bocci G. Drug distribution in tumors: mechanisms, role in drug resistance, and methods for modification. Curr Oncol Rep. 2007; 9: 109-114

16. Netti PA, Berk DA, Swartz MA, et al. Jain RK. Role of extracellular matrix assembly in interstitial transport in solid tumors. Cancer Res. 2000; 60: 2497-2503.

17. Ramanujan S, Pluen A, McKee TD, et al. Diffusion and convection in collagen gels: implications for transport in the tumor interstitium. Biophys J. 2002; 83: $1650-1660$.

18. Stylianopoulos T, Diop-Frimpong B, Munn LL, et al. Diffusion anisotropy in collagen gels and tumors: the effect of fiber network orientation. Biophys J. 2010; 99: 3119-3128.

19. Brown E, McKee T, diTomaso E et al. Dynamic imaging of collagen and its modulation in tumorsin vivo using secondharmonic generation. Nat Med. 2003; 9: 796-800.

20. Jain RK. Transport of molecules in the tumor interstitium: a review. Cancer Res. 1987; 47:3039-3051.

21. Isseri OD, Kars MD, Arpaci $F$ anet al. Gene expression analysis of drug-resistant MCF-7 cells: implications for relation to extracellular matrix proteins. Cancer Chemother Pharmacol. 2009; 65: 447-455.

22. Sherman-Baust CA, Weeraratna AT, Rangel LB, et al. Remodeling of the extracellular matrix through overexpression of collagen VI contributes to cisplatin resistance in ovarian cancer cells. Cancer Cell. 2003; 3: 377-386.

23. Januchowski R, Zawierucha P, Ruciński M, et al. Extracellular matrix proteins expression profiling in chemoresistant variants of the A2780 ovarian cancer cell line. Biomed Res Int. 2014; 2014:365867.

24. Januchowski R, Zawierucha P, Ruciński M et al. Microarray-based detection and expression analysis of extracellular matrix proteins in drug-resistant ovarian cancer cell lines. Oncology Rep. 2014; 32: 1981-1990.

25. St Croix B, Kerbel RS. Cell adhesion and drug resistance in cancer. Curr Opin Oncol. 1997; 9: 549-556.

26. Correia AL, Bissell MJ. The tumor microenvironment is a dominant force in multidrug resistance. Drug Resist Updat. 2012; 15: 39-49.

27. Morin PJ. Drug resistance and the microenvironment: nature and nurture. Drug Resist Updat. 2003; 6: 169-72.

28. Sethi T, Rintoul RC, Moore SM, et al. Extracellular matrix proteins protect small cell lung cancer cells against apoptosis: a mechanism for small cell lung cancer growth and drug resistance in vivo. Nat Med. 1999; 5: 662-668.

29. Dietel M, Bals U, Schaefer B, et al. In vitro prediction of cytostatic drug resistance in primary cell cultures of solid malignant tumours. Eur J Cancer. 1993; 29: 416-420.

30. Ozben T. Mechanisms and strategies to overcome multiple drug resistance in cancer. FEBS Letters. 2006; 580: 2903-2909.

31. Stavrovskaya AA. Cellular mechanism of multidrug resistance of tumor cells. Biochemistry. 2000; 65: 95-106.

32. Varma RR, Hector SM, Clark K, et al. Gene expression profiling of a clonal isolate of oxaliplatin-resistant ovarian carcinoma cell line A2780/C10. Oncol Rep. 2005; 14: 925-932.

33. Januchowski R, Zawierucha $\mathrm{P}$, Andrzejewska M, et al. Microarray-based detection and expression analysis of $\mathrm{ABC}$ and SLC transporters in drug-resistant ovarian cancer cell lines. Biomed Pharmacother. 2013; 67: 240-245.

34. Januchowski R, Zawierucha P, Ruciński M, et al. Drug transporter expression profiling in chemoresistant variants of the A2780 ovarian cancer cell line. Biomed Pharmacother. 2014; 68: 447-53.

35. Januchowski R, Wojtowicz K, Andrzejewska M, et al. Expression of MDR1 and MDR3 gene products in paclitaxel-, doxorubicin- and vincristine-resistant cell lines. Biomed Pharmacother. 2014; 68: 111-117.

36. Januchowski R, Wojtowicz K, Sujka-Kordowska P, et al. MDR Gene Expression Analysis of Six Drug-Resistant Ovarian Cancer Cell Lines. BioMed Res Int. 2013: Article ID 241763.

37. Karsenty G, Park RW. Regulation of type I collagen genes expression. Int Rev Immunol. 1995; 12: 177-185.

38. Mienaltowski MJ, Birk DE. Structure, physiology, and biochemistry of collagens. Adv Exp Med Biol. 2014; 802: 5-29.

39. Chou MY, Li HC. Genomic organization and characterization of the human type XXI collagen (COL21A1) gene. Genomics. 2002; 79: 395-401.
40. Huebner K, Cannizzaro LA, Jabs EW, et al. Chromosomal assignment of a gene encoding a new collagen type (COL15A1) to 9q21 --> q22. Genomics. 1992; 14: 220-224.

41. Yasui $\mathrm{W}$, Oue N, Ito $\mathrm{R}$, et al. Search for new biomarkers of gastric cancer through serial analysis of gene expression and its clinical implications. Cancer Sci. 2004; 95: 385-92.

42. Fischer H, Stenling R, Rubio C, et al. Colorectal carcinogenesis is associated with stromal expression of COL11A1 and COL5A2. Carcinogenesis, 2001; 22: 875-878.

43. Zhu $\mathrm{XL}$, Ai ZH, Wang J, et al. Weighted gene co-expression network analysis in identification of endometrial cancer prognosis markers. Asian Pac J Cancer Prev. 2012; 13: 4607-4611.

44. Vargas AC, McCart Reed AE, Waddell N, et al. Gene expression profiling of tumour epithelial and stromal compartments during breast cancer progression. Breast Cancer Res Treat. 2012; 135: 153-165.

45. Xiong G, Deng L, Zhu J, et al. Prolyl-4-hydroxylase a subunit 2 promotes breast cancer progression and metastasis by regulating collagen deposition. BMC Cancer. 2014; 14:1.

46. Helleman J, Jansen MP, Span PN, et al. Molecular profiling of platinum resistant ovarian cancer. Int J Cancer. 2006; 118: 1963-1971.

47. Karagiannis GS, Petraki C, Prassas I, et al. Proteomic signatures of the desmoplastic invasion front reveal collagen type XII as a marker of myofibroblastic differentiation during colorectal cancer metastasis. Oncotarget. 2012; 3: 267-285.

48. Mikula M, Rubel T, Karczmarski J, et al. Integrating proteomic and transcriptomic high-throughput surveys for search of new biomarkers of colon tumors. Funct Integr Genomics. 2011; 11:215-224

49. Mutolo MJ, Morris KJ, Leir SH, et al. Tumor suppression by collagen XV is independent of the restin domain. Matrix Biol. 2012; 31: 285-289.

50. Harris A, Harris H, Hollingsworth MA. Complete suppression of tumor formation by high levels of basement membrane collagen. Mol Cancer Res. 2007; 5: 1241-1245.

51. Franzke CW, Bruckner P, Bruckner-Tuderman L. Collagenous transmembrane proteins: recent insights into biology and pathology. J Biol. Chem. 2005; 280: 4005-4008.

52. Krenacs T, Kiszner G, Stelkovics E, et al. Collagen XVII is expressed in malignant but not in benign melanocytic tumors and it can mediate antibody induced melanoma apoptosis. Histochem Cell Biol. 2012; 138: 653-667.

53. Parikka M, Kainulainen T, Tasanen $K$, et al. Alterations of collagen XVII expression during transformation of oral epithelium to dysplasia and carcinoma. J Histochem Cytochem. 2003; 51: 921-929.

54. Cho A, Howell VM2, Colvin EK. The Extracellular Matrix in Epithelial Ovarian Cancer - A Piece of a Puzzle. Front Oncol. 2015 ;5: 245.

55. Adur J, Pelegati VB, de Thomaz AA, et al. Second harmonic generation microscopy as a powerful diagnostic imaging modality for human ovarian cancer. J Biophotonics. 2014; 7: 37-48.

56. Provenzano PP, Inman DR, Eliceiri KW, et al. Collagen density promotes mammary tumor initiation and progression. BMC Med. 2008; 6: 11

57. Jazaeri AA, Awtrey CS, Chandramouli GV, et al. Gene expression profiles associated with response to chemotherapy in epithelial ovarian cancers. Clin Cancer Res. 2005; 11: 6300-6310.

58. Cheon DJ, Tong Y, Sim MS, et al. A collagen-remodeling gene signature regulated by TGF- $\beta$ signaling is associated with metastasis and poor survival in serous ovarian cancer. Clin Cancer Res. 2014; 20: 711-723.

59. Erlanson M, Daniel-Szolgay E, Carlsson J. Relations between the penetration, binding and average concentration of cytostatic drugs in human tumour spheroids. Cancer Chemother Pharmacol. 1992; 29: 343-353.

60. Tung YC, Hsiao AY, Allen SG, et al. High-throughput 3D spheroid culture and drug testing using a 384 hanging drop array. Analyst. 2011;136:473-478.

61. Dalton WS. The tumor microenvironment as a determinant of drug response and resistance. Drug Resist Updat 1999; 2: 285-288.

62. Fong ELS, Lamhamedi-Cherradi S-E, Burdett E, et al. Modeling Ewing sarcoma tumors in vitro with 3D scaffolds. Proc Natl Acad Sci USA. 2013; 110: 6500-6505.

63. Miyamoto $\mathrm{H}$, Murakami $\mathrm{T}$, Tsuchida $\mathrm{K}$, et al. Tumor-stroma interaction of human pancreatic cancer: acquired resistance to anticancer drugs and proliferation regulation is dependent on extracellular matrix proteins. Pancreas 2004; 28: 38-44.

64. Aoudjit F, Vuori K. Integrin signaling inhibits paclitaxel-induced apoptosis in breast cancer cells. Oncogene. 2001; 20: 4995-5004. 